\title{
Application of Processing GPR Data and Wave Attributes for Study of the Santa Maria Diapir, Candeias - BA
}

Pablo Uale de Carvalho Silva ${ }^{* 1}$, Marco Antonio Barsotelli' ${ }^{1},{ }^{1}$ UFBA

Copyright 2021, SBGf - Sociedade Brasileira de Geofísica.

This paper was prepared for presentation during the $17^{\text {th }}$ International Congress of the Brazilian Geophysical Society held in Rio de Janeiro, Brazil, $16-19$ August 2021.

Contents of this paper were reviewed by the Technical Committee of the $17^{\text {th }}$ International Congress of the Brazilian Geophysical Society and do not necessarily represent any position of the SBGf, its officers or members. Electronic reproduction or storage of any part of this paper for commercial purposes without the written consent of the Brazilian Geophysical Society is prohibited.

\begin{abstract}
The use of geophysical methods to search for geological features that do not have outcrops is a common methodology for its characterization. In the current research of onshore reservoirs, shale gas is the main target of oil companies, since the amount of oil that was produced in a conventional way has reduced to numbers that with the production of shale gas could generate an initial quantity of derived products hydrocarbons.

The geological features of shales at small depths can be used as analogues for shale reservoirs with gas that are characterized by having micrometric pores, having incipient permeability, and large volumes of gas, mainly dry natural gas better known as methane. Thus, the use of geophysical methods to search for geological features similar to hydrocarbon reservoirs is an auxiliary step in exploration. The behavior, stratifications, structures and lithological information of the area where the shale is located, which is the reservoir rock, are what the research wants to define, so that it can be explored with the greatest amount of information as possible.

To make up for the lack of detailed geological and geophysical studies, it is necessary to develop production technology and new algorithms for processing seismic, petrophysical data and auxiliary methods. Thus, using the study of a shale diapir, as a geological structure, with the GPR Ground Penetrating Radar method is one of the techniques that can assist in the better detailing of structures that may resemble possible shale reservoirs that will be explored. The diapir studied through radargrams aimed to characterize the surface of fractures, stratification, location and its influence as a nesting structure in the surrounding rock. In this work, methods of processing and analyzing wave attributes in GPR data were used, which were of great value and interest for the analysis of radar data. In addition to the usual processing of the GPR, which was done to try to obtain features of the Santa Maria diapir as well as to distinguish it from the sandstone in the studied band, Wave Attributes were applied to the profiles both before and after being processed. Wave attributes are properties extracted from wave data, which can be used in order to emphasize or isolate a wave characteristic, assisting in the interpretation of the data because it can highlight a geological feature or general trend in the data. This methodology was addressed in the work in order to add the possibility of using attributes in GPR data and extracting lithological and structural information from them.
\end{abstract}

